International Journal of Biology, Pharmacy

and Allied Seiences (IJBPAS)

'A B ridge Betusen Caboratory and QRendo'

WwW.ijbpas.com

\title{
STUDY ON THE EFFECT OF INDIGENOUS MICROORGANISMS (IMO) AND SYSTEM OF RICE INTENSIFICATION (SRI) ON THE GROWTH OF RICE PLANT IN NIGERIA
}

\section{ONUOHA, STANLEY CHUKWUDOZIE*1 , ADUO, BRUNO C ${ }^{2}$, OKORAFOR, IKECHUKWU ${ }^{3}$, UDE, IBIAM UDE ${ }^{4}$, ELOM EMEKA ELOM ${ }^{4}$ \\ ${ }^{1}$ Department of Biotechnology, Faculty of Science, Ebonyi State University, Abakaliki, Ebonyi State, Nigeria, ${ }^{2}$ Department of Biotechnology, College of Sciences, Evangel University Akaeze, Ebonyi State, Nigeria, ${ }^{3}$ Department of Microbiology, College of Sciences, Evangel University Akaeze, Ebonyi State, Nigeria, ${ }^{4}$ Department of Microbiology, Faculty of Sciences, Ebonyi State University, Abakaliki, Ebonyi State, Nigeria \\ *Corresponding Author: E Mail: sconuoha@yahoo.com; Tel: +2348032385682}

Received 25 ${ }^{\text {th }}$ Oct. 2019; Revised $18^{\text {th }}$ Nov. 2019; Accepted $25^{\text {th }}$ Dec. 2019; Available online $1^{\text {st }}$ April 2020

https://doi.org/10.31032/IJBPAS/2020/9.4.5002

ABSTRACT

The demand for rice in the market is on the increase hence intensive rice cultivation has been introduced to increase rice production and meet the country's need for food security. This study was carried out to evaluate the effect of indigenous microorganisms and system of rice intensification on rice yield. A high yielding variety of Abakaliki rice (FARO 44) was collected from Ebonyi State University and transferred to Biotechnology Research \& Development green house for nursery. Seeds were sown in soil-filled nylon bags, placed in the green house and allowed to grow for 21 days. Nutrient medium for growth of indigenous microorganisms (IMOs) was formulated using brown sugar, cooked milled rice and water spinach mixture. The treatment was grouped into four. Group 1 was a mixture of IMOs + system of rice intensification (SRI), group 2 was supplemented with IMOs only, group 3 was supplemented with SRI only, while group 4 (control) was normal soil with no added preparation. The soil samples were allowed to stand for 20 days before transplanting. After 21 days in nursery, the rice plants were transplanted onto the soil buckets at the rate of 3 stands per bucket. The plant height, leaf area, leaf wet and dry weight and NPK composition of root and leaf samples were determined. The result showed that plant height differed significantly $(\mathrm{p}<0.05)$ ranging from $9.33 \pm 0.58 \mathrm{~cm}$ to $28.55 \pm 2.45 \mathrm{~cm}$ 
across the treatment groups, the leaf area also differed significantly $(\mathrm{p}<0.05)$ ranging from $12.68 \pm 1.08 \mathrm{~cm}^{2}$ (group 4) to $74.05 \pm 12.95 \mathrm{~cm}^{2}$ (group 1). Meanwhile, the result also revealed that the leaf wet weigh $(0.94 \pm 0.09 \mathrm{~g})$, dry wet $(0.26 \pm 0.06 \mathrm{~g})$ as well as leaf and root nitrogen $(1.543 \pm 0.004 \%$ and $0.736 \pm 0.002 \%)$ and potassium $(0.317 \pm 0.00 \%$ and $0.299 \pm 0.00 \%)$ were significantly $(p<0.05)$ higher in group1 followed by group 2 as compared to other groups. This study has revealed that the use of organic formulations and IMOs has the potential to improve the nutrient uptake as well as performance of cultivated rice species. Hence, there is need to adopt this method in order to boost rice yields.

\section{Keywords: Indigenous microorganism, Rice intensification, Oryza sativa, nutrient uptake INTRODUCTION}

Rice (Oryza sativa) is one of the most important food crops in the world, nourishing approximately $50 \%$ of the population and directly providing $20 \%$ of human calorie intake [1]. It is the most important staple food crop in many developing countries and one of the most important crops grown in Nigeria. They are different rice cultivars that are adapted to a wide range of environments: such as tropical and temperate climates, lowland and highland regions and a wide range of soil types [1]. However, in Nigeria, more than $50 \%$ of rice is grown under paddy environment, while the other half are grown under intensively irrigated systems. The paddy field is a unique agro-ecosystem, where the field is flooded for most of the period of rice cultivation and is left under drained conditions during the off-crop season.

While there are some benefits from continuous flooding of the soil as done in conventional rice production, it has deleterious effects for rice root systems, such as deforming their cortex to create air pockets (aerenchyma) in the roots [2], inhibiting root respiration, and causing degeneration of roots due to hypoxia [3]. Continuous flooding can slow down root metabolism, ion transport, and root and canopy growth at the same time that it suppresses beneficial soil microbes which thrive under aerobic conditions [4]. By rapidly depleting the oxygen level in bulk soil, flooding promotes the growth of anaerobic microorganisms such as fermentative bacteria. Farmers and researchers always find safer approach to maintain soil fertility by using natural resources such as agriculture by-product. 
System of rice intensification (SRI) is considered to be as a smart agro-ecological methodology base on organically grown agriculture product and works by changing the management of plants, soil, water and nutrients [5]. The system of rice intensification (SRI) is an alternate wetting and drying (AWD) method that has been tried in a number of countries in the world. It is a methodology for increasing the productivity of irrigated rice by changing the management of plants, soil, water and nutrients. It involves transplanting young seedlings ( 8 days old) and planting singly at a wider spacing $(20 \mathrm{~cm} \times 20 \mathrm{~cm}-40 \mathrm{~cm} \times 40$ $\mathrm{cm})$. Compost is preferred for nutrients supply and the paddy is dried and wetted alternately. This method has been associated with water saving, because of alternate wetting and drying of rice paddies during the vegetative growth of the crop as opposed to the conventional continuous flooding. AWD enhances water use efficiency in rice production along with increased land and water productivity [6].

Farmers in a number of countries have been able to increase the yields from their current rice varieties with available resources by utilizing the SRI [7, 8]. Higher productivity is achieved by making certain changes in the management of rice plants and the resources upon which these depend on soil nutrients, air, water, soil biota, and solar energy $[\mathbf{9}, \mathbf{1 0}$, 11]. People in most developed countries are demanding a safer food due to the increasing price of chemical fertilizer and environmental pollution. Farmers and researchers always find safer approach to maintain soil fertility by using natural resources such as agriculture by-product.

Indigenous Microorganisms (IMO) is a large group of microorganisms that contribute beneficial soil effects such as nitrogen fixation, mineralization, humus formation, disease suppression and decomposition. Indigenous microorganisms such as photosynthetic bacteria, lactic acid bacteria, fermenting fungi (Aspergillus, Penicillium, Trichoderma) promotes plant growth and development, increases rapid decomposition of organic matter, suppress odors and prevent infestation of harmful insects and maggots [12]. Indigenous Microorganisms Extended Solution (IMO-ES) is a mixture of IMO concentrate, rice wash that have valuable nutrients. IMOES contains beneficial microorganisms that promote plant growth, increase yield and serves as decomposers of biodegradable wastes.

The role of microorganism is beneficially used to increase the amount of macro- and micronutrient as they live naturally in the soil 
and have mutual interaction with the plant [13]. The aim of SRI system is to increase the productivity of rice by minimizing water usage and to solve the water scarcity problem. Utilization of compost, indigenous microorganism (IMO), enzymes from technology farming, arbuscular mycorrhizal fungi (AMF), and effective microbes have been used as soil enhancer [13].

The aim of this study was to evaluate the effect of indigenous microorganisms and system of rice intensification and formulation on growth, physiology, nutrients uptake and rice yield in Ebonyi State, Nigeria.

\section{MATERIALS AND METHODS}

\section{Equipment}

The materials used in this study include soil samples, plastic buckets, meter rule, digital weighing balance, mortar, pestle, beaker, test tubes, incubator, spectrophotometer, and formulated growth medium.

\section{Reagents}

The reagent used was muriate of potash (MOP), triple solubilizing phosphate, ammonium molybdate solution, sulphuric acid, ammonium sulphate, sodium sulphate and locally formulated medium for IMOs generation.

Collection of rice sample and Nursery preparation and transplanting
Seedling of rice (Faro 44) was collected from EBSU Agro-Biz Enterprise pure line collection centre and transferred to Biotechnology R\&D green house for nursery. Seeds were sown in soil-filled nylon bags, placed in the green and allowed to grow for 21 days. The germinated seedlings were watered during the period of nursery. The 21 days old rice plants in nursery were transferred to the sand bucket at the rate of three plants per bucket. The rice plants were watered once every morning to 1 $\mathrm{cm}$ saturation point. The samples were divided into four experimental groups. Group 1 was treated with IMOs and NPK fertilizer, group 2 had only IMOs mixed with the sand bucket, group 3 had neither only NPK fertilizer added to the sand bucket while group 4 had neither IMOs nor NPK fertilizer. This was allowed to grow till maturity will experimental data were collected intermittently.

\section{Medium formulation and generation of indigenous microorganism}

The nutrient medium for the generation of indigenous microorganisms were formulated using locally available biomaterials including brown sugar, cooked milled rice and water spinach. These made up the medium. The generation of indigenous microorganisms was carried out in four stages 
Stage I: Generation of indigenous microorganism I

The cooked rice in a plastic container was placed under bamboo groove for seven days to attract indigenous microorganisms I.

Stage II: Generation of indigenous microorganism II

To further attract other microbial population (indigenous microorganisms II), the indigenous microorganisms I obtained was further mixed with brown sugar in the ratio of $1: 1$ and allowed to stay in a shaded area for another five days to generation indigenous microorganism II.

Stage III: Preparation of fermented plant juice

One litre $(1 \mathrm{~L})$ of water in two plastic buckets was used and $200 \mathrm{~g}$ of sliced water spinach was introduced into one while the other had only $50 \mathrm{~g}$ of brown sugar. Fermented plant juice (FPJ) was prepared by mixing sliced water spinach and brown sugar at the ratio of 1:1 by volume. This was allowed to stand for 6 days before use.

\section{Stage IV:}

The FPJ was mixed with IMOs at the ratio of 1:1. Then $120 \mathrm{~mL}$ of the mixture was introduce $500 \mathrm{~g}$ of soil in each plastic bucket and allowed to stand for 20 days before transplanting.

\section{Determination of plant height}

The height of each rice plant in each group was measured using meter rule after 14, 21, 28 and 35 days of transplanting.

\section{Estimation of leaf Area}

The area was determined by multiplying leaf length by the width. The leaf length and width were measured using meter rule.

\section{Determination of Leaf dry and wet weight}

To determine the leaf wet weight. Freshly collected plant leaves were weighed using digital weighing balance while to determine the dry weight, leaf samples were placed in oven set at $40^{\circ} \mathrm{C}$ for 30 minutes to reduce moisture and allowed to air-dry on lab bench for 24 hours before weighing.

\section{Determination of NPK Content of the Root and Leaf Samples}

\section{Determination of phosphorus content}

Phosphorus (P) was determined using spectrophotometer. Then 4 of the sample was pipette into a $50 \mathrm{~mL}$ volumetrically flask. Then $45 \mathrm{~mL}$ of distilled water and $2 \mathrm{~mL}$ of ammonium molybdate solution were added and mixed properly. After that, $1 \mathrm{~m} 1$ of $5 \mathrm{NCl}_{2} 2 \mathrm{H}_{2} \mathrm{O}$ dilute solutions were added and mixed again, after 5 minutes the measure was taken on the spectrophotometer at $660 \mathrm{~nm}$ wavelength.

\section{Formula:}

Where:

$$
P=\underline{\text { Abs } \times \text { CF } \times \text { DF } \times \text { DF }}
$$$$
\text { Atomic weight of phosphorus }
$$

Abs $=$ Absorbent reading of the spectrophotometer 
$\mathrm{CF}=$ Conversion factor

$\mathrm{DF}=$ Dilution factor

$\mathrm{DF}=$ Dilution factor

\section{Potassium Estimation}

Potassium was obtained by using the flame photometer. The flame photometer was set up by inserting appropriate filter usually by $768 \mathrm{~nm}$ for $\mathrm{K}$ and $589 \mathrm{~nm}$ wave lengths for $\mathrm{Na}$ respectively. This instrument was set to 100 transmittance by taking $2-10 \mathrm{ppm}$ of $\mathrm{K}$ and $\mathrm{Na}$ solution. The standard curve was prepared by plotting transmittance reading against concentration of standard $\mathrm{K}$ and $\mathrm{Na}$ solution.

\section{Nitrogen determination}

The crude protein content was determined using the micro Kjedahi method. The method is based on the wet combustion of the sample by heating with concentrated sulphuric acid in the presence of metallic and other catalysts to effect the reduction of organic nitrogen in the sample to ammonia, which is retained in solution as ammonium sulphate. The digest having been made alkaline, is distilled to remove ammonia which is trapped and titrated.

Procedure: This involves three major steps:

Digestion: sample ( $2 \mathrm{~g}$ ) was weighed inside kjeldahl digestion flask and $25 \mathrm{~mL}$ of concentrated sulphuric acid and a pinch of digestion catalyst (1g of copper sulphate, $20 \mathrm{~g}$ of sodium sulphate and a pinch of selenium powder) was added. Heat was applied in a fume cupboard slowly at first to prevent undue frothing. Digestion continued for 45 minutes until the digest became clear pale green. This was left until completely cool. Distilled water $(20 \mathrm{~mL})$ was added. The digestion flask was rinsed 2-3 times and the rinsing added to the bulk and the volume made up to $50 \mathrm{~mL}$ with distilled water.

Distillation: Markham distillation apparatus was used for distillation. The distillation apparatus was heated and $10 \mathrm{~mL}$ of the digest was added into the apparatus via a funnel and allowed to boil. Sodium hydroxide $(10 \mathrm{~mL})$ of $45 \%$ was added from the measuring cylinder. This was distilled into $50 \mathrm{ml}$ of boric acid indicator.

Titration: The alkaline ammonium borate formed was then titrated directly with $0.01 \mathrm{~N}$ $\mathrm{HCl}$. The titre value which is the volume of acid used was recorded.

$\% \mathrm{~N}=$ Titre x 0.01N HCl x 14.01(At.utN) x100 x 50 x 100 $1000 \times 0.5 \mathrm{~g} \times 10$

\section{Statistical Analysis}

Experimental data generated was analyzed using one way ANOVA while mean separation was carried out using LSD procedure. All analysis carried out using SPSS software version 20 at $\mathrm{p}<0.05$. 


\section{RESULTS}

Effect of indigenous treatment with microorganisms on rice plant height

The result of the effect of indigenous microorganism on plant height showed that all through the study, group 1 treated IMOs and NPK fertilizer recorded significantly $(p<0.05)$ highest plant height $(12.33 \pm 1.04$ $\mathrm{cm}, \quad 19.03 \pm 1.42 \mathrm{~cm}, 22.30 \pm 3.25 \mathrm{~cm}$ and $28.55 \pm 2.45 \mathrm{~cm}$ on $14,21,28$ and 35 days after planting (DAP) respectively) followed by group 2 treated with IMOs only $(11.97 \pm 2.59 \mathrm{~cm}, 16.67 \pm 2.97 \mathrm{~cm}, 21.23 \pm 2.63$ $\mathrm{cm}$ and $27.90 \pm 0.10 \mathrm{~cm}$ on the $14,21,28$ and 35 DAP). Meanwhile, group 3 treated with NPK only recorded plant height of $11.10 \pm 0.85 \mathrm{~cm}$ on $14 \mathrm{DAP}, 14.17 \pm 2.61 \mathrm{~cm}$ (21 DAP), $17.27 \pm 2.53 \mathrm{~cm}$ (28 DAP) and $25.77 \pm 0.25 \mathrm{~cm}$ (DAP). However, group 4 which was just soil sample without any treatment recorded significantly $(p<0.05)$ lowest plant height among the treatment group as shown in Figure 1.

\section{Effect of indigenous treatment with microorganisms on rice Leave area}

The result of the effect of IMOs on rice leaf area showed that the leaf areas differed significantly $(\mathrm{p}<0.05)$ with group 1 (IMOs + NPK) recording the largest leaf area $27.42 \pm 1.66 \mathrm{~cm}^{2}$ on 14 DAP, $47.52 \pm 2.57 \mathrm{~cm}^{2}$ (21 DAP), $50.29 \pm 3.72 \mathrm{~cm}^{2}$ (28 DAP) and
$74.05 \pm 12.95 \mathrm{~cm}^{2}$ on the 35 DAP. This was followed by group 2 treated with only IMOs which recorded $47.77 \pm 10.87 \mathrm{~cm}^{2}$ on 28 DAP and $67.24 \pm 11.15 \mathrm{~cm}^{2}$ on the 35 DAP. However, group 4 which was untreated recorded the lowest leaf area of $12.68 \pm 1.08$ $\mathrm{cm}^{2}$ on the 14 DAP, $24.20 \pm 4.44 \mathrm{~cm}^{2}$ on 21 DAP and $31.50 \pm 3.50 \mathrm{~cm}^{2}$ as shown in Figure 2.

\section{Effect of indigenous treatment with microorganisms on rice Leaf wet weight}

Theresult showed that rice planted on soil samples supplemented with IMOs and NPK fertilizer gained more weight $(0.95 \pm 0.02 \mathrm{~g})$ on 14 DAP compared to group 2 treated with just IMOs $(0.87 \pm 0.05 \mathrm{~g}), \quad$ group 3 supplemented with only NPK fertilizer $(0.71 \pm 0.02 \mathrm{~g})$ and group $4(0.56 \pm 0.02 \mathrm{~g})$ which was unsupplemented. The same trend was observed on the rest of the cultivation period with group 1 recording significantly $(p<0.05)$ higher wet weight $(1.33 \pm 0.04 \mathrm{~g}$ on $35 \mathrm{DAP})$, group $2(1.27 \pm 0.06 \mathrm{~g}$ on $35 \mathrm{DAP})$, group $3(1.08 \pm 0.17$ on $35 \mathrm{DAP})$ and group 4 which recorded lowest weight $(0.94 \pm 0.09 \mathrm{~g}$ on 35 DAP) as shown Figure 3.

Effect of indigenous treatment with microorganisms on Leaf dry weight

The result showed that on the 14 DAP, there was a significant $(p<0.05)$ difference in the leaf dry weight of rice sample given different treatment. On 14 DAP, Group 1 had the 
highest dry leaf weight $(0.35 \pm 0.04 \mathrm{~g})$ followed by group $2(0.27 \pm 0.04 \mathrm{~g})$, group 3 $(0.21 \pm 0.04$ g) while group 4 recorded significantly lowest dry leaf weight $(0.09 \pm 0.01 \mathrm{~g})$. Similar pattern was observed in day 21, 28 and 35 after planting, with group 1 recording significantly higher $(p<0.05)$ leaf dry weight on the 35 DAP $(0.59 \pm 0.08$ g) followed by group 2 $(0.50 \pm 0.04 \mathrm{~g})$. However, group 3 and 4 recorded low leaf dry weight $(0.41 \pm 0.04 \mathrm{~g}$ and $0.26 \pm 0.06 \mathrm{~g}$ respectively) as shown

\section{Figure 4.}

Effect of indigenous treatment with microorganisms on NPK composition of leaf and root of rice plant

The result of the effect of NPK composition of leaf and root sample of the different treatment groups showed that rice plant cultivated on soil buckets supplemented with IMOs+SRI (Group 1) had the highest NPK composition $(1.191 \pm 0.004 \%, 0.017 \pm 0.00 \%$ $0.271 \pm 0.00 \%)$ in leaf and $(0.663 \pm 0.002 \%$ $\mathrm{N} ; 0.013 \pm 0.00 \% \mathrm{P}$; and $0.222 \pm 0.00 \% \mathrm{~K}$ ) in root samples. This was followed by Group 2 (treated with IMOs only) which recorded NPK composition of $1.018 \pm 0.003 \% \mathrm{~N}$; $0.015 \pm 0.00 \mathrm{P}$ and $0.243 \pm 0.00 \% \mathrm{~K}$ in leaf and $0.387 \pm 0.002 \% \mathrm{~N} ; 0.011 \pm 0.00 \% \mathrm{P}$ and $0.204 \pm 0.00 \% \mathrm{~K}$ in root samples on the 21
DAP, while Group 4 which was not treated with either IMOs or SRI recorded the lowest leaf NPK content $(0.528 \pm 0.003 \quad \% \quad \mathrm{~N}$; $0.014 \pm 0.00 \% \mathrm{P}$ and $0.245 \pm 0.00 \% \mathrm{~K}$ ) and root NPK content $(0.294 \pm 0.002 \quad \mathrm{~N}$; $0.010 \pm 0.00 \% \mathrm{P}$ and $0.181 \pm 0.00 \% \mathrm{~K}$ ) as shown in Figure 5. There was significant $(p<0.05)$ difference in the NPK content of the different treatment groups as shown in Figures 5, 6, 7 and 8 .

The same trend was observed on the 28 DAP (Figure 6) and 35 DAP (Figure 7) where the NPK composition was significantly higher on the leaf and root of group $1(+\mathrm{IMO}+\mathrm{SRI})$ $(1.543 \pm 0.004 \quad \% \quad \mathrm{~N} ; \quad 0.022 \pm 0.00 \quad \mathrm{P}$; $0.354 \pm 0.00 \% \quad \mathrm{~K}$ content in leaf and $0.736 \pm 0.002 \% \quad \mathrm{~N} ; \quad 0.015 \pm 0.00 \quad \mathrm{P} \quad$ and $0.299 \pm 0.00 \mathrm{~K}$ in root samples) than any other treatment group. This NPK concentration was followed by group 2 (+IMOs-SRI), group 3 (-IMOs+SRI). However, group 4 (IMO-SRI) recorded the lowest NPK concentration in both leaf and root samples as shown in Figure 7.

In general, the nitrogen $(\mathrm{N})$ content was observed to be significantly high across the different treatment groups followed by potassium (K) content but phosphorus content was significantly low as shown in Figures 5, 6 and 7. 


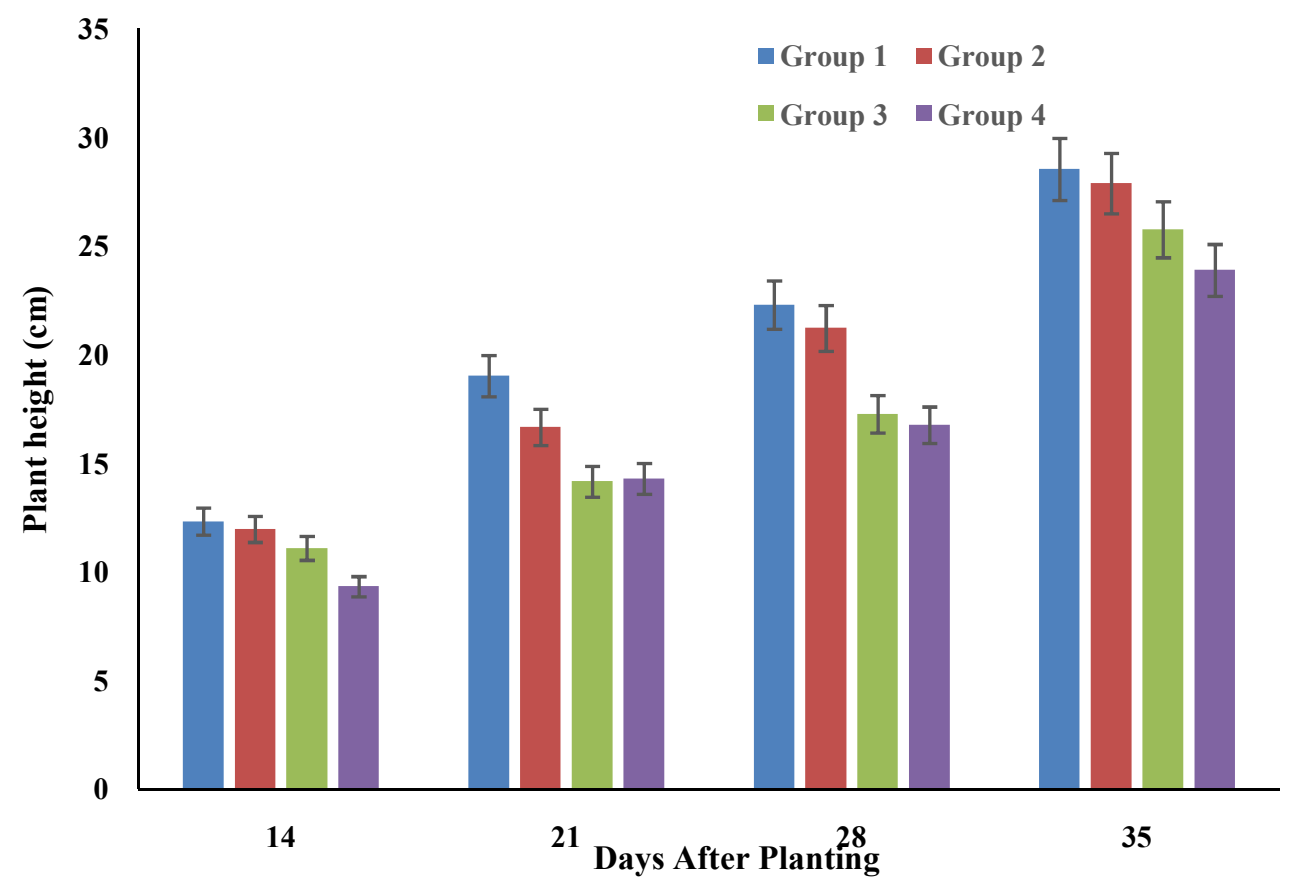

Figure 1: Effect of Indigenous microorganisms on plant height

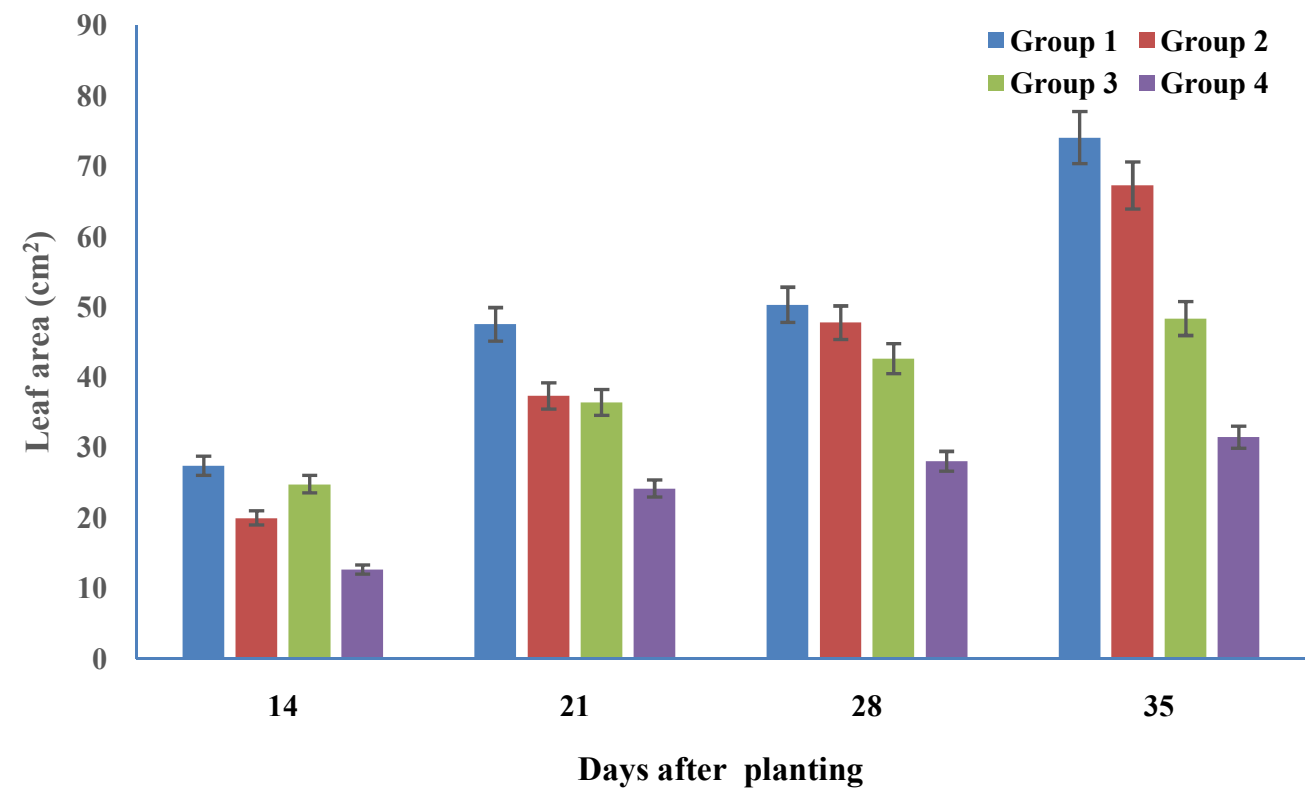

Figure 2: Effect of indigenous treatment with microorganisms on rice Leave area 


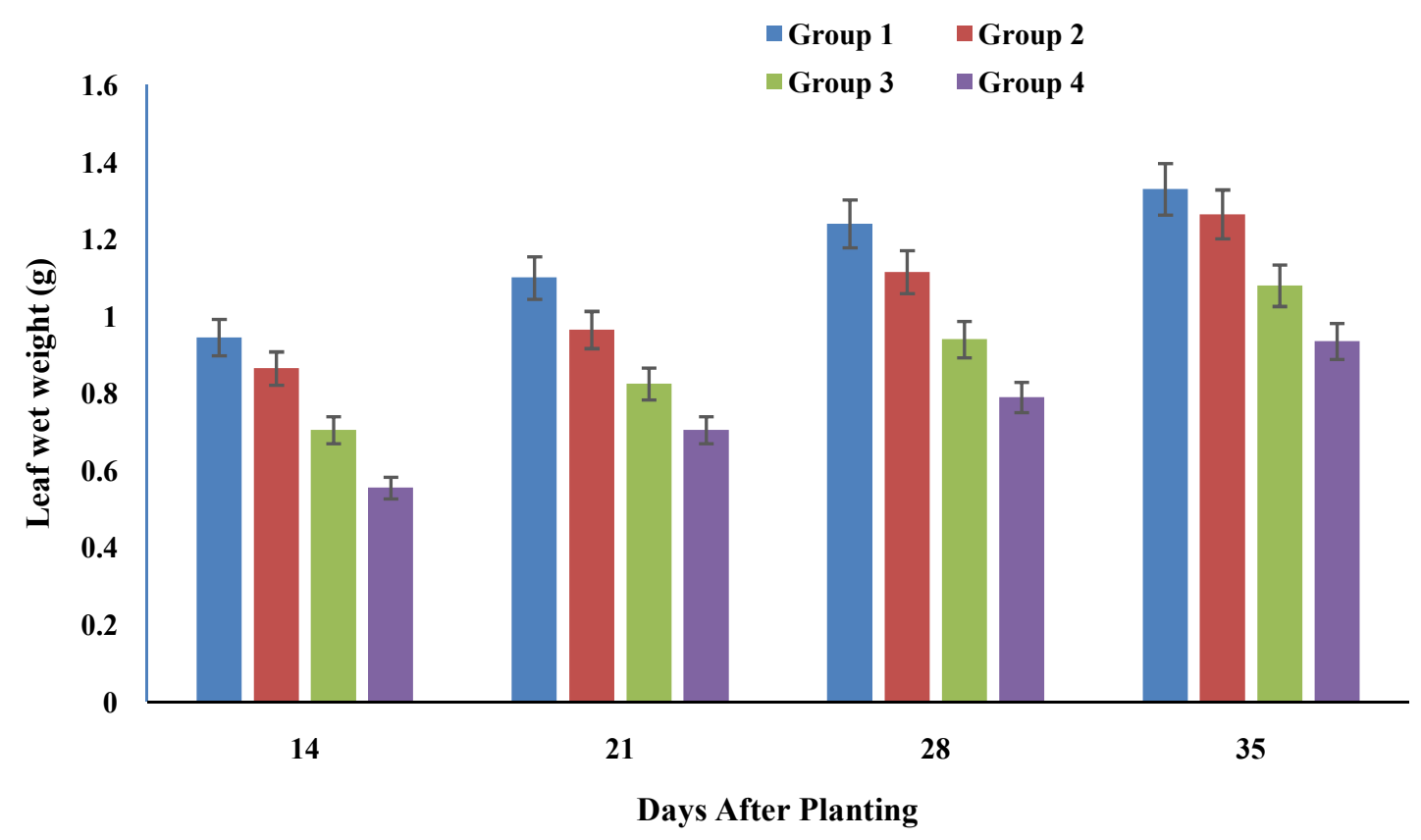

Figure 3: Effect of indigenous microorganisms on Leaf wet weight of rice samples

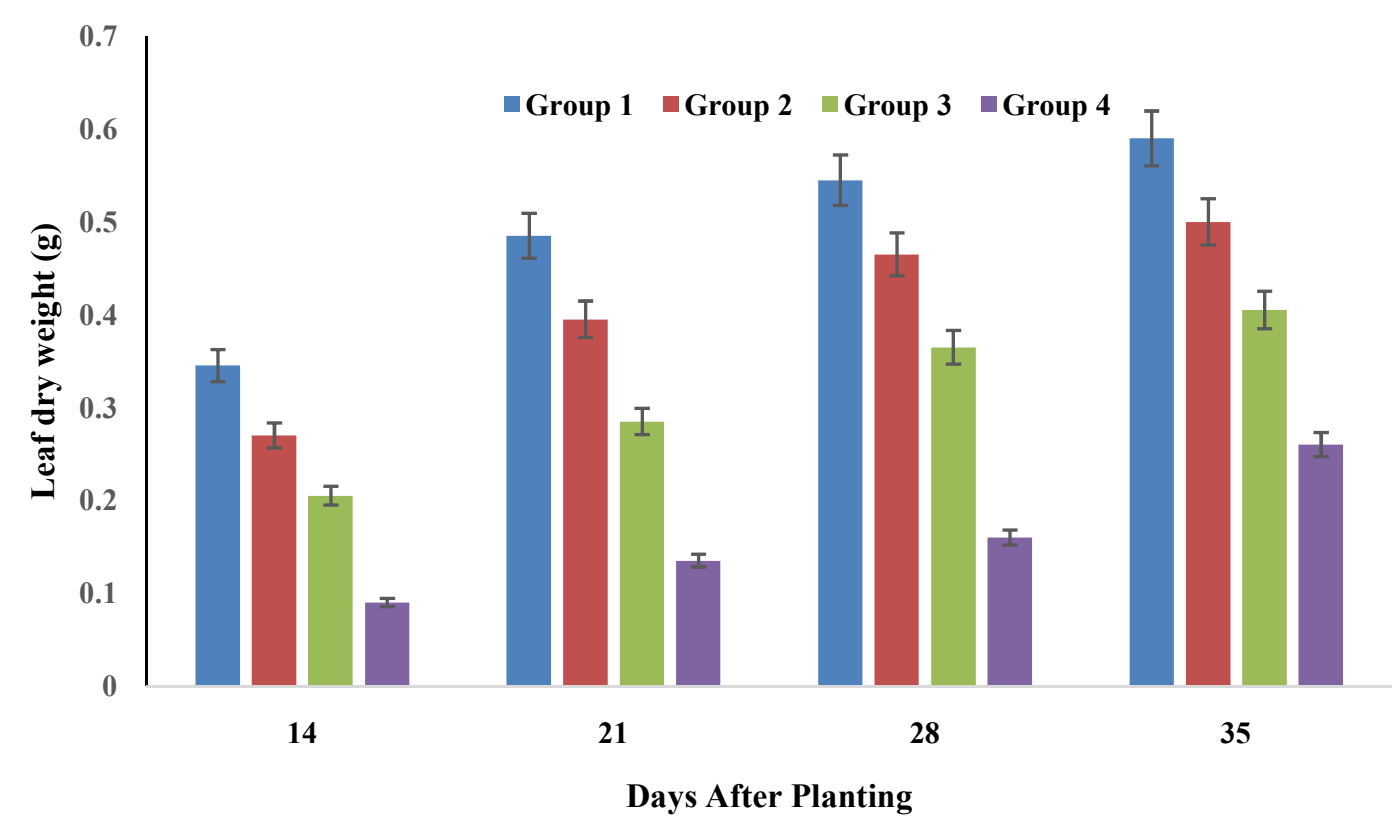

Figure 4: Effect of indigenous microorganisms on Leaf dry weight of Rice samples 
DAY 21

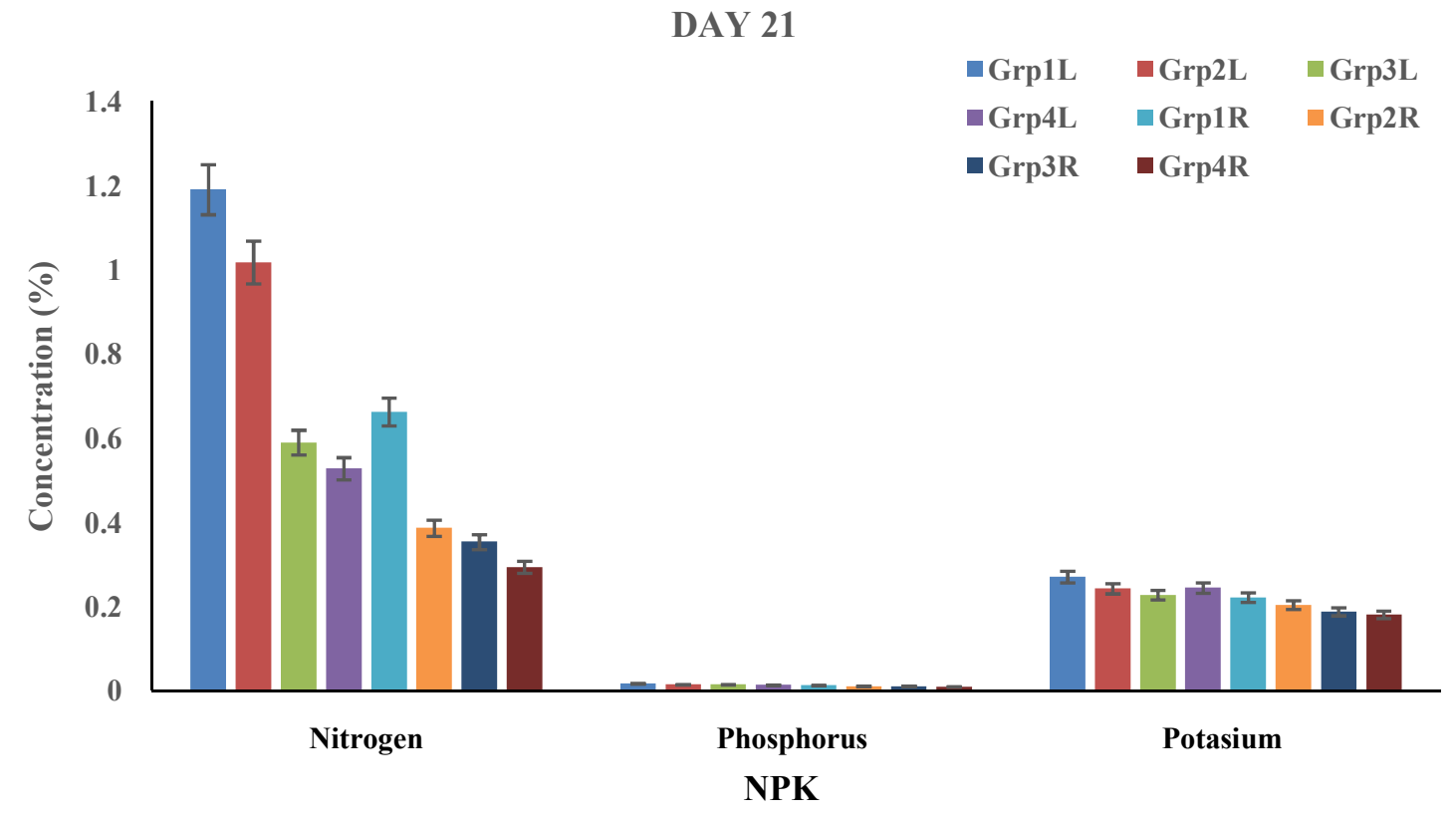

Figure 5: NPK content of rice leaf and root samples on 21 DAP

Key: Grp1L=Group 1 leaf, Grp2L=Group 2 leaf, Grp3L=Group 3 leaf, Grp4L=Group 4 leaf.

Grp1R=Group 1 root, Grp2R=Group 2 root, Grp3R=Group 3 root, Grp4R=Group 4 root.

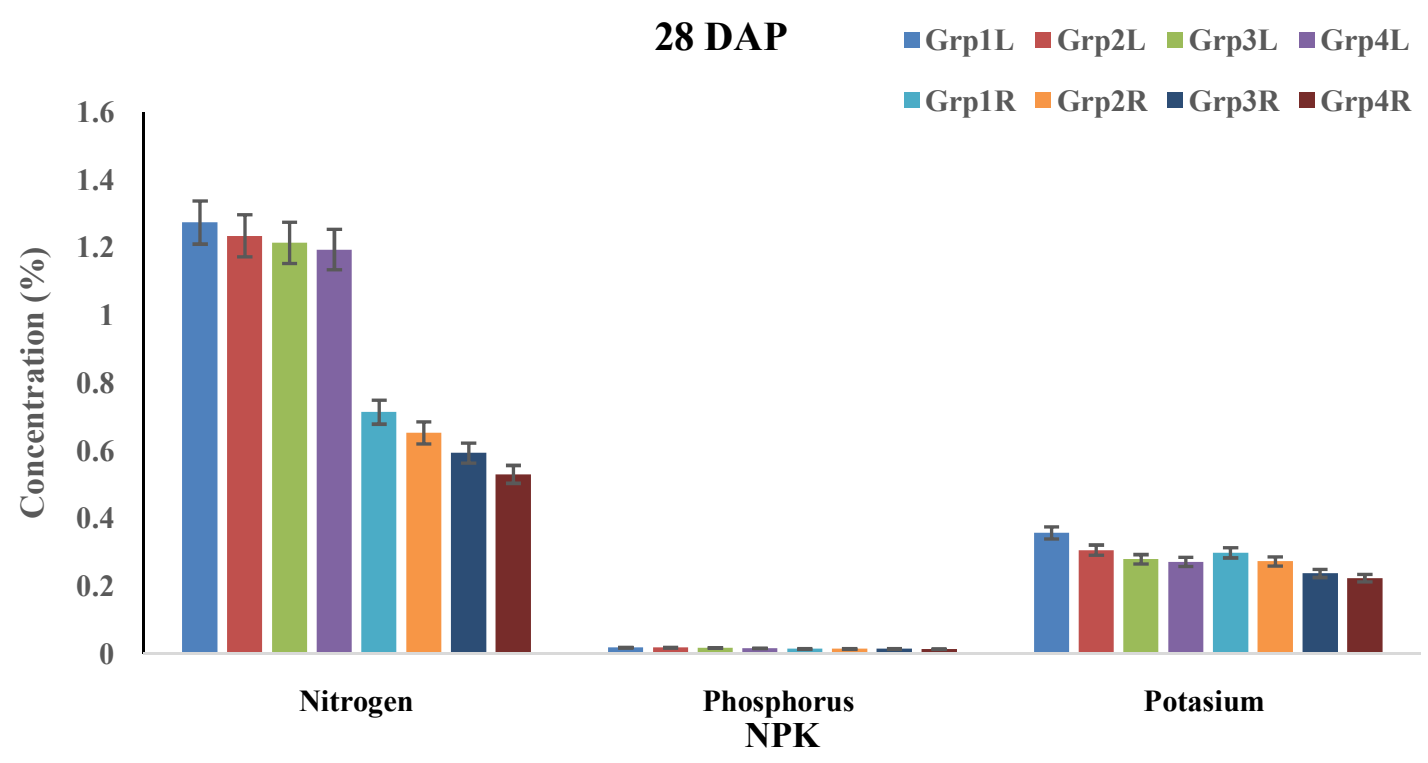

Figure 6: NPK content of rice leaf and root samples on 28 DAP 
35 DAP

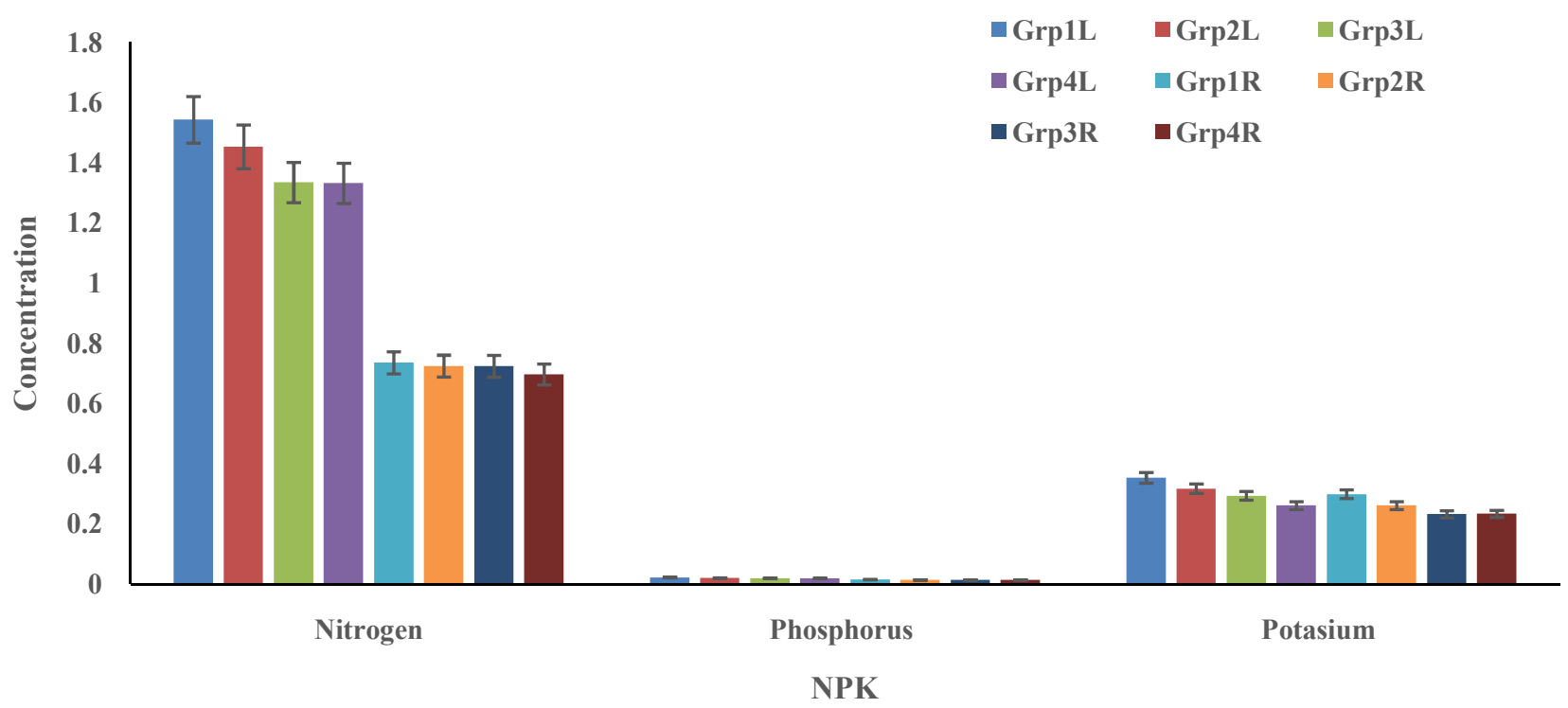

Figure 7: NPK content of rice leaf and root samples on 28 DAP

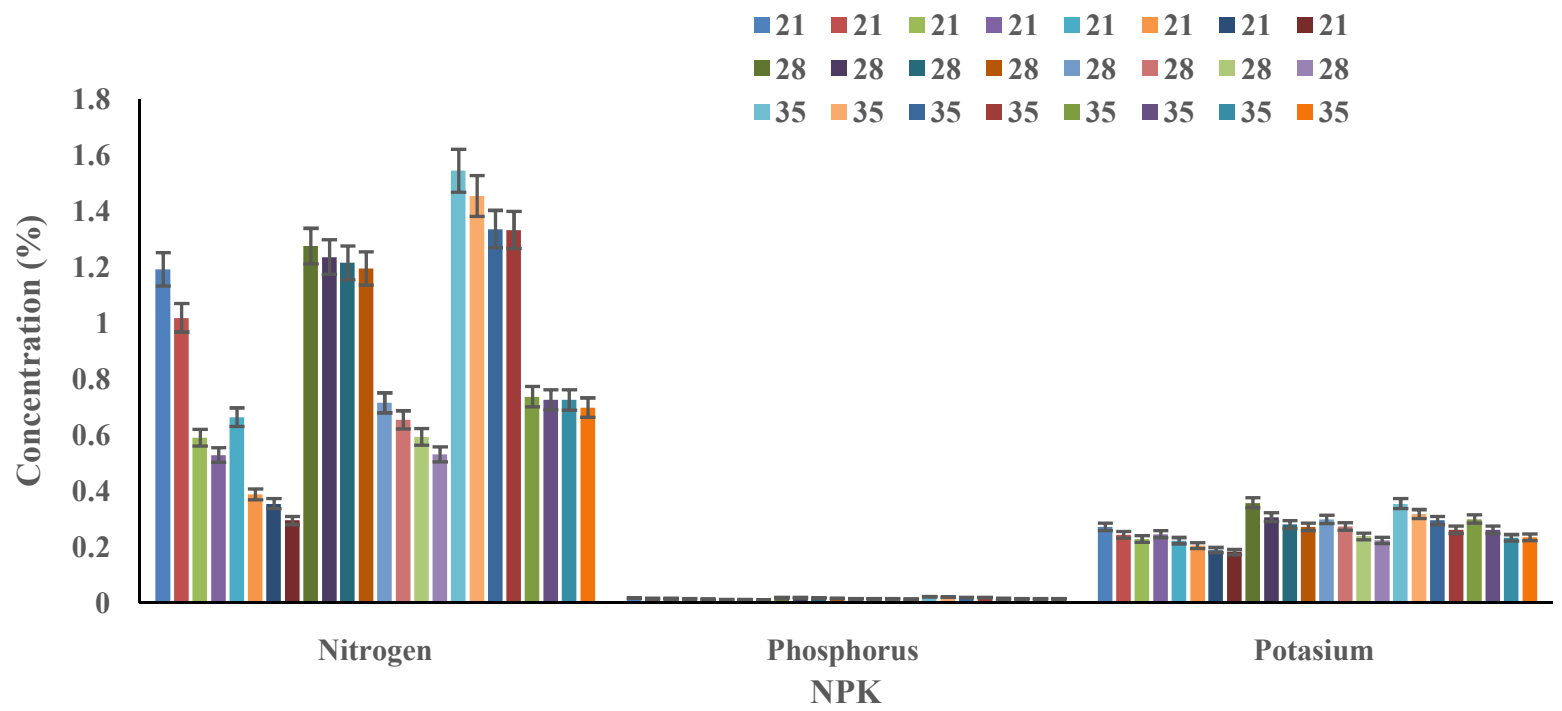

Figure 8: Effect of IMOs and SRI on the NPK content of rice leaf and root samples on during the experimental period Key: Grp1L=Group 1 leaf, Grp2L=Group 2 leaf, Grp3L=Group 3 leaf, Grp4L=Group 4 leaf. Grp1R=Group 1 root, Grp2R=Group 2 root, Grp3R=Group 3 root, Grp4R=Group 4 root 


\section{DISCUSSION}

Rice (Oryza sativa L.) is the staple food for people in many countries around the world. Intensive rice cultivation has been introduced to increase rice production and meet the country's need for food security. However, the system of intensive rice cultivation will bring to the negative impact to the environment [14]. The present study was carried out to evaluate the effect of indigenous microorganisms and system of rice intensification and formulation on growth, physiology, nutrients uptake of rice plant in Ebonyi State.

The result of the effect of indigenous microorganism on plant height showed that plant height ranged from $9.33 \pm 0.58 \mathrm{~cm}$ in group 4 (-IMOs-SRI) to $12.33 \pm 1.04 \mathrm{~cm}$ in group 1 (+IMOs+SRI) on $14 \mathrm{DAP}$ and from $23.90 \pm 0.40 \mathrm{~cm}$ (group 4) to $28.55 \pm 2.45 \mathrm{~cm}$ (group 1) on 35 DAP. The result reveal that the plant grown on sand bucket supplied with IMOs and SRI i.e., NPK fertilizer grew better followed by rice plants supplemented with IMOs (group 2), group 3 (supplemented with NPK fertilizer only) while group 4 which was not supplemented recorded lowest plant height across the cultivation period. This suggested that the IMOs may have supported plant growth since rice group 2 performed better that group 3. The trend in plant growth across the group was group $1(+\mathrm{IMOs}+\mathrm{SRI})$ $>$ group 2 (+IMOs-SRI) > group 3 (IMOs+SRI) > group 4 (-IMOs-SRI) (Figure 2). Similar trend was reported by [15] who stated that there was significant increase in plant height with increasing DAP of rice treated with IMOs. This suggests that application of IMOs enhances soil fertility and nutrient uptake. In line with this statement, [15] observed that the growth of rice plant was boosted with application of SRI Anak formulation and concluded that higher plant height of paddy treated with IMO and SRI Anak formulation indicated that application of organic enhancer (IMO and SRI Anak formulation) will increase the soil fertility. The similar result was also reported by [16] who reported that the plant and microorganism live symbiotically in natural environment. Beneficial microorganis ms such as IMOs and other local formulation produce nutrients, hormones and antibiotics in small quantities and plant absorb it. They opined that certain inorganic fertilizers allow the plant to skip this process and plant has to absorb the nutrient in larger quantities. This is not a good process as it can burn to the roots system which may cause the death of the seedling or it will undergo slow growth in later stage. 
The result also showed that there was significant difference on leave area as the rice in group 1 had higher leaf area followed by group 2, group 3 then group 4 in descending order across DAP. This observation was similar to the report by [16] who reports that their result showed there was significant difference on leaf area among all the treatments on 14 and 21 DAP. They further stated that Increases in leaf area during 21 and 35 DAP might be due to higher content of $\mathrm{N}$ in IMOs formulation of SRI. Synergism from foliar spray of IMOs formulation as well as interaction between application of IMO and available nutrient in the media help the rice leaf area and healthier [15]. These contributed to the increase in photosynthesis rate. Result showed that the application of IMO and SRI formulation is potentially contributed to better rice yield in the actual plantation in the field. This statement is particularly true because rice in group 1 (+IMOs+SRI) performed better followed by group 2 hence were able to utilize the nutrient in the soil.

Similarly, the wet and dry weight followed the same trend as group1 $>$ group2 $>$ group $3>$ g roup4. Similarly, [15] also reported that results from their study show that $\mathrm{T} 1$ (+IMOs+local formulation) gave higher value of fresh and dry leaves weight than other treatments. This increase in weight in group 1 and 2 can be attributed to increase in photosynthetic activities as well as uptake of nutrient from the soil suggested recently by [15].

Meanwhile, the result also showed that the NPK content were significantly higher in group $1>2>3>4$. This confirmed the earlier assertion that IMOs helps in the uptake of nutrient by rice root via symbiotic association which is crucial in making nutrients more bioavailable and converting them into a more utilizable form. In a similar study, [15] reported that on $21 \mathrm{DAP}$, content of $\mathrm{N}$ and $\mathrm{P}$ in leaf tissue showed significant difference and stated that rice treated with IMOs and SRI (T1) has the highest nutrient uptake of $\mathrm{N}$ and $\mathrm{P}$, although the $\mathrm{K}$ content in their rice did not show any significant difference in the leaves samples. They further reported that rice treated with IMO and SRI Anak formulation (T1) exhibited the highest increment rate of $\mathrm{N}, \mathrm{P}$ and $\mathrm{K}$ content by 2.78 , 2.89 and $0.5 \%$ in root tissue than control and other treatment from 21 to 35 DAP (Fig. 6ac). There were significant difference among all treatments either with or without IMO and SRI Anak formulation on the content of $\mathrm{N}$ in root tissue on 35 DAP. P content in root tissue of paddy rice treated with T1 exhibit $2.71 \%$ higher than control on 35 DAP. 


\section{CONCLUSION}

This study has revealed that the use of organic formulations and IMOs has the potential to improve the nutrient uptake as well as performance of cultivated rice species. This method is simple and applicable hence there is need to adopt it in rice farming in Ebonyi State as it can help ensure food security and reduce environment denudation caused by excessive use of chemical fertilizers.

Conflict of interest: The authors declare they have no conflict of interest.

\section{REFERENCES}

[1] Zeigler R and A. Barclay (2000). The relevance of rice, Rice. 1:3-10

[2] Kirk, G. and D. Bouldin (2001). Speculations on the operation of the rice root system in relation to nutrient uptake. In: Simulation and systems. Pudoc, Wageningen, UK. Pp. 193203.

[3] Kar, S., S. Varade, T. Subramanyam and B. Ghildyal (2004). Nature and growth pattern of rice root system under submerged and unsaturated conditions. Riso, 23:173-179

[4] Barison, J. and N. Uphoff. (2011). Rice yield and its relation to root growth and nutrient-use efficiency under SRI and conventional cultivation: an evaluation in Madagascar. Paddy and Water Environment,9:65-78

[5] Gopalakrishnan S and R.M Kumar (2013). Assessment of different methods of rice (Oryza sativa L) cultivation affecting growth parameters, soil chemical, biological, and microbiological properties, water saving, and grain yield in rice. Paddy and Water Environment 3: 122.

[6] Carrijo, D.R., M.E Lundy and B.A Linquist (2017). Rice yields and water use under alternate wetting and drying irrigation: a meta-analysis. Field Crops Research, 203:173-180.

[7] Kabir, H. and N. Uphoff (2007). Results of disseminating the system of rice intensification with farmer field school methods in Northern Myanmar. Experimental Agriculture, 43: 463-476.

[8] Namara, R., D. Bossi., P. Weligamage and I. Herath (2008). The practice and effects of the system of rice intensification (SRI) in Sri Lanka. quarterly Journal of International Agriculture,47:1-12.

[9] Ceesay, M., W.S Reid, E.C.M Fernandes and N. Uphoff (2006). 
The effects of repeated soil wetting and drying on lowland rice yield with system of rice intensification (SRI) methods. International Journal of Agricultural Sustainability, 4: 5-14.

[10] Lin, X.Q., D. F Zhu, S.H Cheng and Y.P. Zhang (2009). Tillering patterns and the contribution of tillers to grain yield with hybrid rice and wide spacing. In Assessments of the system of rice intensification. Proceedings of International Conference, Sanya, China, 1(4). 125-129

[11] Thakur, A.K., N. Uphoff and E. Antony (2010). An assessment of physiological effects of System of Rice Intensification (SRI) practices compared to recommended rice cultivation practices in India. Experimental Agriculture, 46: 77-98.

[12] Sanchez, R. G., D.S. Barrientos and J.L. Galindez (2018). Effect of indigenous microorganism extended solution (IMO-ES) on basmati rice. International Journal of Agricultural Technology, 14(7): 1871-1882.

[13] Siti, Z.S., A. Nur, S.J. Abdul, A. Amirul and A. Farzad (2017).
Effects of indigenous microorganis $\mathrm{m}$ and system of rice Intensification formulation on growth, physiology, Nutrient uptake and rice yield. Bangladesh J. Bot. 46(1): 433-438,

[14] Sampanpanish, P. (2012). Effect of organic fertilizer use in rice paddy to reduce greenhouse gases. $2^{\text {nd }}$ International Conference on Environmental and Agriculture Engineering. IPCBEE vol. 37 IACSIT Press, Singapore. Pp. 152161.

[15] Sakimin,S.Z., A.A. Nur, A. S.J. Abdul, A. Amirul and A. Farzad (2017). Effects of indigenous microorganism and system of rice intensification formulation on growth, physiology, nutrient uptake and rice yield. Bangladesh Journal of Botany, 46(1): 433-438.

[16] Samin JPA 2011. Effect of indigenous microorganisms (IMO) in the growth and yield performance of tomato (lycopersicon esculentum) The Philippines' Department of Science and Technology (DOST). Central Bicutan, Taguig City, Philippines. 